\title{
The Role Of Measurement Theory In Supporting The Objectives Of The Financial Statements
}

Saratiel Weszerai Musvoto, North West University - Vaal Triangle Campus, South Africa

\begin{abstract}
This study emphasises the fact that the objectives of the financial statements are not compatible with the principles that establish measurement in the social sciences, and that they therefore cannot be considered to be measurement objectives. The concept of measurement presupposes the comprehension of the principal state and consequently the objectives of a measurement discipline only make measurement sense in the presence of a theory of measurement in which they are contained. Currently, accounting is considered to be a measurement discipline with complete measurement objectives, even in the absence of a measurement theory that incorporates the objectives of the measurement process. In this study the principles of the representational theory of measurement (a theory that establishes measurement in the social sciences) are used to emphasise that the objectives of the financial statements are not measurement objectives unless they are supported by a theory of measurement. Hence the financial statements cannot contain measurement information until a theory of measurement is established that incorporates the objectives of the accounting measurement processes.
\end{abstract}

Keywords: measurement objectives; financial statements; representational measurement; empirical true value; measurement theory

\section{INTRODUCTION}

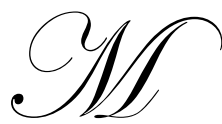

easurement is a term which is in common usage in contemporary accounting literature. Its frequent use in accounting has made it virtually synonymous with accounting practice. The definition of accounting also implies that measurement is part of the traditional accounting methodology. For example, Wolk et al. (2001), Kirk (2005) and the IASB (2009) all define accounting as the art of measuring and communicating accounting information. This definition gives the impression that the accounting concept of measurement is based on firm foundations of measurement that would be expected of any measurement discipline in its class.

The theory of measurement that establishes measurement in the social sciences is the representational theory of measurement, which is also known as the modern principles of measurement. As accounting is currently classified as a social science one would expect accounting measurement practices to be compatible with the general principles of measurement that are applicable to measurements in their class.

According to Ryan et al. (2002:118), every process of measurement must be based on a theory of measurement. They argue that a theory of measurement incorporates the objectives of the process of measurement, states the standard against which measurements can be compared and specifies the units of measurement. This viewpoint suggests that a theory of measurement is incomplete if it does not include the objectives of the measurement process. It also follows that objectives of measurement cannot exist in the absence of a theory of measurement. 
The process of preparing financial statements is considered to be a process of measurement (IASB, 2009) Furthermore, twelve objectives of the financial statements have also been identified (Wolk et al, 2001). The presence of objectives in what is regarded as a measurement process legitimises the activity of preparing financial statements as a process of measurement. However, accounting research (e.g. Chambers, 1997; Gilman, 1939; Ijiri, 1975, 1967; Littleton, 1953; Paton and Littleton, 1940; Staubus, 1985; Staubus, 2004; Sterling, 1966, Musvoto, 2011), has established the consensus that the accounting discipline has not succeeded in creating a theory of accounting measurement from the observation of accounting practices of measurement. However, every process of measurement must have a theory of measurement (Narens, 2002). If this is true, it suggests that the lack of a theory of accounting measurement casts doubt on the belief that current accounting practices are practices of measurement. This creates confusion with regard to whether the accounting concept of measurement is compatible with the principles of the representational theory of measurement.

The reason why accounting practices have not given rise to a theory of measurement is not known in accounting (see Chambers, 1997; Staubus, 1985; Staubus, 2004; Walker and Jones, 2003). According to Narens, (2002) the process of measurement is carried out only if there is an established purpose to be achieved by the process. It is clear from this statement that the purpose of measurement should be identified first before measurement takes place. Both the theory of measurement and the objectives of measurement must complement each other. In other words, the purpose of measurement must be compatible with the process of measurement before measurement can take place. If this is the case, it follows that if accounting is a measurement discipline as implied in the literature, then the objectives of accounting should reflect an underlying theory of accounting measurement. Therefore the absence of a theory of measurement suggests that the accounting discipline has not fully recognised the role of measurement theory in complementing the objectives of the financial statements.

In view of the discussion above, this study aims to examine, within the context of the principles of representational measurement, the role of a theory of measurement in complementing the objectives of measurement. This study commences with a brief description of the theory of measurement in the social sciences in section 2. This is followed by a discussion of the role of measurement in the preparation of financial statements in section 3, followed by a discussion of the accounting implications of the principles of representational measurement in section 4. The study continues with a discussion of the measurement implications of the objectives of accounting in section 5. It ends with conclusions and recommendations in section 6.

\section{THE CONCEPT OF A THEORY OF MEASUREMENT IN THE SOCIAL SCIENCES}

A theory of measurement is an indispensable component for setting the objectives of a measurement discipline. According to Ryan et al. (2002), the purpose of a theory of measurement in the social sciences is to state the objectives of the measurement process, describe how measurement should be established and the standards against which measurements can be compared. This means that measurement cannot take place in the absence of comparison and in the absence of a specified goal and a specified path for achieving the goal. Similarly, in defining measurement in the social sciences, Caws (1959:3) also states: "Measurement presupposes something to be measured, and, unless we know what that something is, no measurement can have any significance". This emphasises that measurement can only take place if there are identified or selected attributes of a set of objects that are of interest to measure. That is to say, we need to know what we are measuring for measurement to take place. Moreover, according to Caws (1959:5), measurement can also be defined as "the assignment of particular mathematical characteristics to conceptual entities in such a way as to permit an unambiguous mathematical description of every situation involving an entity and the arrangement of all occurrences of it in a quasi serial order." It is clear from this definition that a random assignment of mathematical characteristics is excluded from the definition of measurement in the social sciences. Orbach (1978) also points out that although the precise definition of measurement requires a mathematical formulation, measurement in the accounting context may be described as the process of identifying selected attributes of a set of objects (or events) and assigning numbers (or mathematical entities, such as vectors) to objects so that the properties of the attributes are 'preserved' or 'represented' by the assignment. The author points out that by defining measurement in this way, all measurements must be representative of the underlying phenomenon and must also be unique. In other words, for measurement to occur the underlying phenomena must also exist. Since the concept of the uniqueness of representations in measurement is only possible when a scale of measurement is present (Luce, et al., 1971), it may be argued that a scale is 
foundational to measurement in the social sciences. Furthermore, the following definition by Narens (2002:760) shows the importance of a scale of measurement:

A qualitative structure $\mathbf{X}$ is selected to capture the domain $\mathbf{A}$ of interest; a mathematical representing structure $\mathbf{N}$ is selected to measure $\mathbf{X}$ in terms of the scale $\mathbf{S}$ of homomorphisms of $\mathbf{X}$ into $\mathbf{N}$; and meaningfulness is identified with a form of invariance associate $\mathbf{S}$, e.g. with $\mathbf{S}$-invariance.

This definition of measurement has come to be known as the representational theory of measurement or the modern principles of measurement. This concept requires the specification of the empirical relational structure, the scale of measurement and the abstract structure or the representing structure. If this holds true, it follows that measurement theory in the social sciences dictates that a measurement should be completely described by the existence of the underlying phenomena and the specification of a scale of measurement. In this case the scale is unique and invariant. Here it may be argued that it encloses the objectives of the measurement process. Hence, if accounting is to be considered a measurement discipline, then its theories must specify a scale of measurement and the property to be measured.

\section{THE PERCEIVED ROLE OF MEASUREMENT IN THE PREPARATION OF FINANCIAL STATEMENTS}

The current perception in accounting is that the concept of measurement plays a pivotal role in the recognition of economic phenomena in financial statements. Recognition is defined as the process of incorporating an item that meets the definition of an element of the financial statements, and also meets the recognition criteria in the financial statements (IASB, 2009). According to the IASB framework (2009) for financial reporting, an item that meets the definition of an element of financial statements should be recognised in the statements if it has a cost or value that can be measured with reliability. This suggests that there is no accounting transaction that can be recognised in the financial statements unless it has a cost or value that can be measured with reliability. It also implies that no financial statements can be prepared in the absence of a process of measuring value. It is expected that accounting should have a theory of measurement that clearly states the foundations of measuring the cost or the value of an item that meets the definition of an element of the financial statements.

The IASB framework (2009) for financial reporting defines measurement as the process of determining the monetary amounts at which the elements of financial statements are to be recognised and carried in the statement of comprehensive income and the statement of financial position. Evidently, the monetary amounts are used to represent the cost or value of an element that is recognised in the financial statements. It would also be expected that the accounting discipline should have a theory that describes the determination of the monetary amounts at which the elements of the financial statements are carried in the statement of comprehensive income and the statement of financial position. It is clear from this that no financial statements can be prepared in the absence of measurement. It follows that measurement forms the major part of the methodology for preparing financial statements. It can be concluded from this that no financial statements can be prepared in the absence of measurement.

\section{IMPLICATIONS OF MEASUREMENT FOR ACCOUNTING}

In this section the implications of measurement for accounting are discussed. The purpose of accounting is inferred partly from its definition and partly from other statements extracted from the accounting literature. In the accounting literature the term measurement is commonly used to mean the assignment of monetary units to accounting phenomena. The purpose of accounting is to represent the empirical relational structures of accounting phenomena by monetary units. An analysis of the definition of accounting also suggests that the accounting concept of measurement hinges on the assignment of monetary units to accounting phenomena. For instance, Bierman (1963: 501) defines accounting as follows:

Accounting is the art of measuring and communicating financial information. 
This definition indicates that accounting is a measurement discipline that specialises in measuring financial phenomena: it therefore specialises in measuring phenomena that can be expressed in monetary terms. Thus it can be concluded that the purpose of accounting is to create financial information through the act of measurement.

Similarly, Wolk et al. (2001:172) (see also AICPA, 1953, Para 5) state:

Accounting is the art of recording, classifying and summarising in a significant manner and in terms of money, transactions and events which are, in part at least, of a financial character and interpreting the results thereof.

The use of the word 'classifying' suggests that accounting is a measurement discipline. According to Stevens (1946), classification is the most basic form of measurement. If the nature of accounting is such that it is a measurement discipline, then the accounting concept of measurement comes to mean no more than traditional accounting methodology. Accounting is also described as an explanatory discipline that utilises measurement as its primary mode of description (Larson, 1969). Therefore the summarisation of transactions and events in terms of money is considered in the accounting discipline to be an act of measuring accounting phenomena. This view is supported by Abdel-Magid (1979:355), who states:

The property subject to measurement in an exchange transaction is exchange value, which is measured by the monetary numerosity at the time of exchange. At the time of exchange, the equality of ratios can be verified by an empirical operation.

The general belief in the accounting concept of measurement is based on the representation of the empirical relational structure of value by an abstract structure of monetary units. Furthermore, the accounting standards indicate that monetary units are a measurement of value in accounting. For example, the IASB (2009, Para 83) states:

An item that meets the definition of an element should be recognised if:

It is probable that any future economic benefits associated with the item will flow to or from the entity; and the item has a cost or value that can be measured with reliability.

It is clear from this extract that even expectations are measurable in the accounting discipline. This is consistent with the principles of the representational theory of measurement. Expectations have legitimate properties in the present that are measurable (Orbach, 1978). The extract also points out that value and cost are attributes that are measurable in accounting: the domain of the measurement functions in accounting is cost or value.

However, in spite of the suggestions that the objective of accounting is to measure accounting phenomena, it should be pointed out that a thorough analysis reveals that the accounting concept of measurement falls short of the requirements of the representational theory of measurement. For example, the summarisation of transactions and events in terms of money referred to above (AICPA, 1953) cannot be an act of measurement. It is alleged that there is no property which is measured by the financial statements apart from the numerosity of monetary units (Willett, 1987). This suggests that the concept of value is not adequately defined in the accounting discipline. What is more, value is an ambiguous concept that is not an intrinsic property of an accounting entity (Stamp, 1981). Stamp also points out that as a result of the ambiguous nature of value there is no general agreement among accountants on the meaning or relevance of 'value'. Yet according to Decoene et al. (1995), in the representational theory measurement magnitudes are historically and theoretically determined reflections of quantitative aspects of objectively existing entities and not merely the outcome of metricisation or measuring procedures. In this case value is not objective and therefore it cannot be measured.

Goldberg (2001) asserts that the primary objective of accountants is to ascertain and present the truth. Since accounting is considered to be a measurement discipline, this statement may be interpreted to mean that accounting measurements reflect the truth. These points of view imply an exactness associated with accounting that is wholly inconsistent with the approximating character of measurement. Measurement is never any more than an 
approximation (Larson, 1969). This means that measurements are never a true reflection of the object of measurement. Margenau (1959:136) is also very clear on the approximation nature of measurement when he states:

An empirically 'true' value of a measured quantity does not exist. What passes for the truth among the results of measurement is maximum likelihood; a concept that attains meaning if a statistical sample of differing measured values is available.

This would suggest that there are no exact measurements. Every measurement discipline must therefore introduce the concept of error in its measurements. It follows that, if accounting is a true measurement discipline, it should be able to deal with the concept of error.

The American Accounting Association (1971) suggests that accounting is indispensable in measuring and reporting organisational wealth and its changes. The necessity of determining preformed theoretical constructs of the properties or qualities to be measured in accounting is implied by the major premise that accounting is a measurement discipline and the minor premise that all measurement presupposes something to be measured (Larson, 1969). However, the problem is that the attributes of wealth that are the subject of measurement are not specified. That is, there is no specification of the property of a class of accounting objects which it is of use and interest to measure in the quantification of wealth. However, every measurement scheme requires the specification of the property of a class of objects which it is of use and interest to measure (Chambers, 1997). If the attributes that are supposed to be measured are not specified, it is not possible for measurement to take place. It is not possible for researchers to measure something that is unknown to them. In addition, there is no specification of the appropriate measurement procedures to be employed in assigning numbers to represent those properties.

This analysis has not exhausted all the points on which issue may be taken with the belief that accounting is a measurement discipline. However, sufficient points have been identified to place in serious doubt the belief that measurement is part of the traditional accounting methodology. Therefore it can be concluded from this analysis that the accounting concept of measurement is not compatible with the principles of measurement.

\section{REPRESENTATIONAL MEASUREMENT AND THE OBJECTIVES OF THE FINANCIAL STATEMENTS}

The concept of measurement presupposes the achievement of a goal. Unless the goal of measurement is known, measurement is not possible. Caws (1959:3) is very clear on this: "Measurement presupposes something to be measured, and unless we know what that something is, no measurement can have any significance."

This means that measurement presupposes the comprehension of the principal state. Therefore it follows that one cannot represent by numbers phenomena which one does not know. Since accounting is concerned with user needs, a set of objectives relating to user needs stands at the apex of the metatheory (Wolk et al. 2001). If accounting measurement should be congruent with the objectives of financial statements, it can be inferred that comprehension of the objectives of the financial statements implies comprehension of the principal state of accounting phenomena.

In an attempt to establish the objectives of financial statements, the accounting discipline set up the Trueblood committee (AAA, 1971) to investigate and compile a report on the objectives of financial statements. These objectives have been used in this study because they were arrived at from an empirical study. The objectives of the financial statements compiled by the Trueblood committee can thus be regarded as reflecting the true empirical objectives of preparing financial statements. The committee compiled twelve objectives of financial statements. If, as the literature claims, the accounting discipline is a measurement discipline (e.g. AICPA, 1941; Bierman, 1963; Goldberg, 2001; IFRS, 2009; Wolk et al., 2001), then these objectives should be compatible with the principles of representational measurement. An analysis of the compatibility of the objectives of financial statements with representational measurement is carried out below:

The first objective of the financial statement states (Wolk et al., 2001:182):

The basic objective of the financial statements is to provide information useful for making economic decisions. 
The first objective links accounting information to decision making. It places emphasis on processes external to accounting. This suggests that users of accounting information must understand the perspective of a measurement approach in order to use accounting measurement information.

However, it should also be pointed out that it is not possible for users of accounting information to know with certainty whether such information is useful for a particular decision. Ijiri (1975) notes that decisions are made under conditions of uncertainty. Consequently it is clear that a decision maker can only estimate the likelihood of an event happening based on his past experience. It is also evident from this that the exact nature of the event cannot be known in advance, therefore the exact nature of the accounting information that is needed to predict the event is also not known with certainty.

It is imperative that the exact use to which accounting information produced for decision-making purposes will be put should be known with certainty. The principles of the representational theory of measurement require that all measurement information should be meaningful (Luce and Narens, 1994). If accounting is a discipline that produces measurement information, then accounting information must be meaningful. Churchman and Ratoosh (1959) argue that an empirical hypothesis, or any statement of fact, which uses numerical quantities is empirically meaningful only if its truth-value is invariant under the appropriate transformations of the numerical quantities involved. It can be inferred from this that meaningful statements are so because of the use to which the information may be put. If the use to which this information may be put is not known with certainty, accounting information may not be considered meaningful.

The second objective states (Wolk et al., 2001:182):

An objective of the financial statements is to serve primarily those users who have limited authority, ability, or resources to obtain information and who rely on financial statements as their principal source of information about an enterprise's economic activities.

The second objective identifies the primary audience of the financial statement. The specification of the primary audience undermines the pervasive nature of accounting measurements among all the investors of the business entity and the investors of different business entities. If information is produced for a specific group of people, it undermines its comparability among all users of accounting information. The primary audience of the financial statement is clearly identified in the above excerpt as those users who have limited authority and resources to obtain information, and those who rely on financial statements as their principal source of information. If the information in these financial statements is intended for the less informed investors, it means that the objective of measurement will be biased towards the goals of these investors. This is because measurement presupposes a goal to be achieved (Caws, 1959:3). As a result, the choice of scales to use and attributes to measure in accounting will be biased towards the information needs of less informed users.

The third objective states (Wolk et al., 2001:182):

An objective of the financial statements is to provide information useful to investors and creditors for predicting, comparing, and evaluating potential cash flows to them in terms of amount, timing, and related uncertainty.

The third objective identifies investors and creditors as the primary users of the financial statement. However, it is not absolutely clear why it is necessary to single out investors and creditors in the light of the Trueblood committee's value judgment that user decisions and information are largely homogeneous (see Wolk et al., 2001). This suggests that there is a lack of clarity in the accounting discipline as to what information should be produced for users.

Nevertheless, since the second objective specifies that financial statements should be intended for users with limited ability to obtain information, and states: "An objective of the financial statements is to serve primarily those users who have limited authority, ability, or resource to obtain information and those who rely on financial statements as their principal source of information about an enterprise's activity", then it can be inferred that investors and creditors have limited ability in obtaining accounting information. Evidently, the numerical representations of the empirical relations of this information are also biased towards the investors and creditors. The 
information content of the measures that describe this accounting information is determined by the information needs of the investors and creditors. This makes accounting information useless to users other than investors and creditors.

The third objective also suggests that accounting information should be useful for predictive purposes. This means that the measures that describe the empirical properties of accounting phenomena should be useful for predictive purposes. Ryan et al. (2002) point out that predictions can only be made from information that is theoretical. Thus, if accounting information is used for predictive purposes, then accounting measurements must be theoretical, and if this information is used for predictive purposes, then there must be a theory of accounting measurement.

The fourth objective states (Wolk et al., 2001:182):

An objective of the financial statements is to provide users with information for predicting, comparing, and evaluating enterprise earning power.

The fourth objective identifies the uses of financial information, such as for predicting, comparing and evaluating an enterprise's earning power. The earning power of a business is determined for a specific period (IASB, 2009). However, the activities of an entity are not stopped to determine its earning power during a particular period. An arbitrary cut-off point is imposed on the business activities, which are otherwise continuous. Moreover, the periodicity of income determination requires the going concern assumption (Sterling, 1979). This means that the present measurement of income is dependent upon subsequent events. However, measurement occurs at a specific point in time regardless of what happened in the past or what will happen in the future (Sterling, 1979). In other words, present measurements cannot be dependent on past or future events. Consequently, it is clear that income is not currently measurable as it is dependent on future events. This objective is thus not compatible with the principles of the representational theory of measurement.

The fifth objective states (Wolk et al., 2001:182):

An objective of the financial statements is to supply information that is useful in judging management's ability to utilise enterprise resources effectively in achieving the primary enterprise goal.

The fifth objective implies that the information contained in financial statements can be used to judge the abilities of management. The objective also highlights the functions of management as extending beyond those of simply safeguarding the assets, to effectively and efficiently utilising assets in order to carry out the enterprise's objective of maximising future cash flows. Furthermore, it can be inferred that this objective requires that management be accountable to the investors for the activities of the enterprise and their consequences for these investors.

From this discussion it is clear that this objective implies that accounting information must be measured in accordance with the goals of a specific entity. It follows that the empirical significance and the meaningfulness of accounting measurements should be interpreted with reference to a specific firm. Consequently, accounting information cannot be compared beyond the borders of a specific entity. Baiman (1990) supports this view, pointing out that the rights and responsibilities of the principals and agents are specified in the mutually agreed upon employment contracts. As a result, the production of accounting information is governed by specific contracts. It is therefore evident that accounting information is relative to a social setting. That is, it describes the relationships within a social setting. Thus accounting information is not comparable across different accounting entities unless these entities are in an identical social setting.

The sixth objective states (Wolk et al., 2001:182):

An objective of financial statements is to provide factual and interpretive information about transactions and other events, which is useful for predicting, comparing, and evaluating enterprise earning power. Basic underlying assumptions with respect to matters subject to interpretation, evaluation, prediction, or estimation should be disclosed. 
The use of the word 'factual' in the sixth objective implies that the information that should be contained in the financial statements should be true, accurate, authentic, historical and genuine. It is not currently possible for accounting systems to provide information that is factual. This is because there is no measurement that is factual or accurate. Measurement is never any more than an approximation. Margenau (1959:136) is very clear about this:

An empirically true value of a measured quantity does not exist. What passes for truth among the results of measurement is maximum likelihood, a concept that attains meaning if a significant statistical sample of differing measured values is available.

Moreover, the sixth objective of the financial statements does not take into account the agent's involvement with the information (see Ijiri, 1975: x). As a result the objective tends to encourage subjective information assuming that it is not biased. Furthermore, the financial statements contain book entries (Gouws \& Van der Poll, 2004). These authors point out that book entries are a creation of the mind, and not based on observed reality. This suggests that book entries cannot be empirically verified, as they do not represent reality. According to Luce et al. (1971), phenomena that cannot be empirically verified are not measurable. Thus it is clear from this that book entries are not measurable. In addition, the use of estimates in financial statements also means that the information contained in them is not factual. An 'estimate' is a judgment that is made without the exact details or figures about the size, amount and cost of something (Hornby, 2005). Consequently estimates do not correspond to real-world phenomena, and thus they cannot be classified as measurements or as factual. As has been outlined above (Luce $e t$ al., 1971), measurements must represent reality and must be a true representation of reality (subject to a specified error) before they can qualify as measurements.

The seventh objective states (Wolk et al., 2001:182):

An objective is to provide a statement of financial position useful for predicting, comparing, and evaluating enterprise earning power. This statement should provide information concerning enterprise transactions and other events that are part of incomplete earnings cycles. Current values should also be reported when they differ significantly from historical cost. Assets and liabilities should be grouped or segregated by the relative uncertainty of the amount and timing of prospective realisation or liquidation.

The statement of financial position contains the values of assets and liabilities. Since the values of assets and liabilities lie in the future (Sterling, 1968), this means that it is not possible to measure the empirical properties of assets in the present. Moreover, the statement of financial position is prepared under the going concern assumption, and as a result the present measurements of the elements of the balance sheet are dependent on subsequent events. This means that the true values of these elements can never be known since subsequent events always lie in the future. In addition, Sterling (1979), points out that measurement occurs at a specific point in time regardless of what has happened before or what is still to come. It is evident from this that past and future occurrences are not relevant to present measurements. Consequently one can see that it is not possible to have measurements of the values of assets or liabilities in the balance sheet that are dependent on subsequent events. It is clear, then, that the values of assets and liabilities in the balance sheet do not meet the requirements of measurements. This suggests that the financial reporting requirements of this objective are not compatible with the principles of the representational theory of measurement.

Classification is fundamental to every measurement system. Mattessich (1964:60) points out that classification is the ultimate basis of measurement. He argues that a class symbol has to be assigned to an empirical object or event initially for measurement to occur. It follows that what is needed for measurement to commence is a qualitative description of the characteristic that is to be measured, in other words a name or an identity has to be assigned to the phenomenon that is subject to measurement. Obviously, one can see that such an assignment of identity provides the phenomenon in question with a class.

If assets and liabilities are being grouped by the relative uncertainty of the amount and timing of the prospective realisation it means that the attribute that is being measured is the relative uncertainty and timing of the realisation. It is therefore evident that value is an attribute of assets and liabilities that is measurable using current values, historical cost or present values, and consequently it also follows that the "relative uncertainty and timing of 
the realisation of assets or liabilities" is an attribute of the value of assets and liabilities that is measurable by classification.

There is no specification in the accounting literature, however, of the property of 'uncertainty' that is used to classify assets and liabilities in the balance sheet. According to Narens (2002), it is necessary to specify the property that is subject to measurement before measurement can take place. It can be inferred from this that one cannot measure something one does not know. Furthermore, there is no specification of a scale of some kind which makes it possible to distinguish the extent to which assets and liabilities possess the specified property of relative uncertainty. A scale of measuring 'uncertainty' establishes the amount of uncertainty in the realisation of the value of an asset or a liability. The absence of such a scale implies that the amount of uncertainty in the realisation of the value of an asset or liability can only be subjective. This consequently suggests that it is not possible to measure accounting phenomena under the seventh objective of the financial statements.

In addition, there is no specification of the factors to be considered in determining the relative uncertainty and timing of the realisation of the amounts the items in the statement of financial position have in common. In fact, in the current accounting literature, there is no clear stipulation of the financial properties of objects and events which decision makers can properly use to make judgments about or legitimate comparisons between particular companies. It is necessary to give a precise identity to what is being compared so that a standard for such comparisons can be established. Therefore this objective suggests that the accounting concept of measurement is not compatible with the principles of the representational theory of measurement.

The eighth objective states (Wolk et al., 2001:182):

An objective is to provide a statement of periodic earnings useful for predicting, comparing, and evaluating enterprise earning power. The net result of completed earnings cycles and enterprise activities resulting in recognisable progress toward completion of incomplete cycles should be reported. Changes in the values reflected in successive statements of financial position should also be reported, but separately, since they differ in terms of their certainty of realisation.

The objective points out that the preparation of a statement of periodic earnings is necessary in the evaluation of the earning potential of an enterprise. According to Sterling (1979), the income statement specifies a particular time interval. In the statement of comprehensive income, the economic effects of different economic events that occur at different points in the time interval are aggregated to determine the earning power of the business during that particular time interval. It is debatable, however, whether the figure of periodic earnings arrived at can be considered to be a measurement of anything. Sterling (1979:223) points out that measurement occurs at a specific point in time regardless of what has happened before or what will happen after that specific point in time. This indicates that measurements should take into account events that are occurring at that specific point in time. It is thus evident that the aggregation of the economic effects of different economic events that have occurred at different points in time to determine periodic earnings is not compatible with the concept of measurement.

The objective also indicates that the preparation of a statement of financial position is necessary for the determination of the financial health of a company at a specific point in time. The statement of financial position contains the values of assets and liabilities. Sterling (1968) notes that statements prepared under going concern are provisional and dependent on subsequent events. Therefore one can infer that the values of the assets and liabilities in the statement of financial position are dependent on subsequent events. It has been noted above (Sterling, 1979) that measurement occurs at a specific point in time regardless of what will happen in the future, which implies that the values of the assets and liabilities in the balance sheet cannot be measurements. They are dependent on events that have not yet occurred. For this reason they are not compatible with the principles of representational measurement.

Furthermore, it is alleged that the true income of a firm cannot be calculated until the firm is dissolved (Sterling, 1968). This means that all the values prepared under the going concern assumption are provisional. Income can never be determined under going concern. The aspect of comparability cannot be achieved since the true values of the elements of the financial statements are not known under going concern. As outlined earlier, all 
measurements occur at a specific point in time, and so the dependence of the value of income on subsequent events does not reflect the qualities of a measurement.

The ninth objective states (Wolk et al., 2001:182):

Another objective is to provide a statement of financial activities useful for predicting, comparing, and evaluating enterprise-earning power. This statement should report mainly on factual aspects of enterprise transactions having or expected to have significant cash consequences. This statement should report data that require minimal judgment and interpretation by the preparer.

The objective asserts that the aim of the financial statements is to provide a statement of financial activities that reports factual information on the activities of the enterprise. This means that the statement intends to convey objective information. However, this is not possible since financial statements are prepared on the going concern basis. Information prepared on the going concern basis is dependent on subsequent events (Sterling, 1968), and subsequent events are always in the future and can never be known.

The ninth objective consistently uses of the term 'factual'. This term is not consistent with the concept of measurement. Measurement is never anything more than an approximation (Larson, 1969). All measurements involve an element of error. An empirically 'true' value does not exist. What passes for truth among the results of measurement is maximum likelihood; a concept that attains meaning if a significant statistical sample of differing measured values is available (Margenau, 1959). This implies that measurements do not reflect the truth, but only approximations of the truth. This objective suggests an exactness of accounting quantifications that is not compatible with the principles of measurement, indicating that the ninth objective is not compatible with the principles of the representational theory of measurement.

The tenth objective states (Wolk et al., 2001:182):

An objective of the financial statements is to provide information useful for the predictive process. Financial forecasts should be provided when they will enhance the reliability of users' predictions.

This objective points out that the information in financial statements must have predictive powers. In order to be able to predict phenomena, one must have empirical information about the phenomena in the present. Sterling (1968) notes that financial statements prepared under the going concern basis are provisional and that the information in these statements is dependent on subsequent events. It is clear then from this that the present magnitude of information in financial statements cannot be known because subsequent events always lie in the future and cannot be known, therefore the information contained in financial statements does not represent objectively existing entities. Furthermore, for information to have predictive powers it must be theoretical. According to Churchman and Ratoosh (1959), the function of a theory is to summarise information about empirical phenomena and predict the behaviour of the phenomena. In other words, the purpose of a theory is to explain the future behaviour of a phenomenon and to provide dependable information about it. However, the information contained in financial statements cannot be theoretical as it is dependent on future events. Thus it does not correspond closely to real-world phenomena.

The eleventh objective states (Wolk et al., 2001:182):

An objective of financial statements for governmental and not-for-profit organisations is to provide information useful for evaluating the effectiveness of the management of resources in achieving the organisation's goals. Performance measures should be quantified in terms of identified goals.

This objective highlights the point that financial statements should provide information to enable users to judge the performance of an entity. McLean (2006) points out that the performance is always measured in relation to some point of reference. In this case it is in relation to some identified goals. Each organisation has its own goals. Different organisations might choose different reference points for the evaluation of performance. Furthermore, if the organisation has multiple stakeholders, it is possible that they could adopt different reference points for 
determining the performance of an entity. It is important to note that the property that is of use and interest to measure in determining performance must be specified and it must be measurable. However, authors such as Chambers (1997), Ryan et al. (2002), Staubus (2004) and Musvoto \& Gouws (2010) note that the property that is of use and interest to measure in the accounting discipline is not specified. It follows that although this objective specifies the need to measure performance, the accounting discipline has not as yet developed a system of determining performance that meets the requirements for performance measurement.

The twelfth objective states (Wolk et al., 2001:182):

An objective of financial statements is to report on those activities of the enterprise that affect society which can be determined and described or measured and which are important to the enterprise in its social environment.

This objective places emphasis on the interaction between the private goals of shareholders and the goals of the public as a whole, with the goals of a business enterprise that are important to its social environment being required to be congruent with those of society. The organisation is expected to have a moral obligation towards society at large. However, some studies have shown that corporations are anything but moral. For example, the Arthur Andersen \& Co (1979) survey report estimated the cost of government regulation of corporations in 1977 at $\$ 2.6$ billion. In the report there is no estimate whatsoever of the benefits of regulation. Moreover, Belkaoui (1989:7) states:

For example, in 1986 a bill introduced in the House of Representatives required auditors to report immediately to federal authorities any suspicions of fraud that they detected in a company's books. The bill also called for the financial statements to be signed by the individual auditor, not just the firm. Because of the pressures put forth by the accounting profession the bill did not pass.

Given this view one may suggest that it is difficult to conceive of a corporation that is interested in advancing the interests of society ahead of its own: the accounting profession is interested in advancing its own interests and not those of society. As a result, measures of the impact of an enterprise's activities on society are likely to be biased in favour of the entity. According to Boyce et al. (1994), measurements must be common in the community under discussion. This means that measures used by an entity must be accepted by society at large.

However, if the choice of the measures of the attributes of the enterprise that affect society depends on the entity, then the public has no say in what may be reported by the entity. Ijiri (1975: ix) points out that management is involved with the information and cannot report negatively on their activities. Worse still, the public does not provide any input into the production of the information they receive. Consequently, the public might have a different reference point for determining what are and what are not satisfactory measures of those activities that affect the enterprise's social environment. It can be concluded from this that society does not have a say in what the firm chooses to report and describe. If this is the case, it follows that under the current financial reporting regime it is not possible for the accounting discipline to construct objectives of the financial statements that are compatible with the principles that establish measurement in social scientific disciplines.

\section{CONCLUSIONS AND RECOMMENDATIONS}

This study has shown that the accounting literature considers the concept of measurement to be fundamental to the preparation of financial statements, and in fact does not regard the preparation of financial statements as possible in the absence of measurement. However, although the literature suggests that measurement is an indispensable part of accounting, an analysis of the definition, purpose and objectives of accounting indicates that the accounting concept of measurement is not compatible with the scientific principles of measurement. In fact, measurement plays a very small or no role at all in the preparation of financial statements. Some of the main issues raised can be summarised as follows:

The accounting literature implies an accuracy of accounting measurements that is inconsistent with the concept of measurement. Measurement is never anything more than an approximation, and all measurements contain an error of some sort. Accounting measurements do not reflect the concept of error. 
There is no specification of the objects or the properties of objects which are the subject of measurement in accounting. Value or costs are not precisely defined in accounting. This is inconsistent with the principles of the representational theory of measurement, which require that the object of measurement must be empirically identifiable and testable.

There is no theory of accounting measurement that incorporates the objectives of the measurement processes. This makes the objectives of the financial statements vague and subject to interpretation, and they consequently lack clear boundaries of interpretation.

In the light of the above findings, it is recommended that the accounting discipline should re-evaluate the role of measurement in the preparation of financial statements. Furthermore, it is recommended that if accounting is to be considered a measurement discipline, its objectives, definition and the preparation of financial statements should be sustained by an underlying theory that supports the processes of measurement.

\section{AUTHOR IFNORMATION}

S Wedzerai Musvoto is a senior lecturer in Financial Management and Accounting at the School of Accounting Sciences of the North-West University's Vaal Triangle Campus. He received his PhD from the University of Pretoria in 2008. Dr Musvoto is also affiliated with the Association of Chartered Certified Accountants and the Chartered Institute of Management Accountants. His research interests include accounting measurement, risk management and the implications of modern principles of measurement on finance theory development. E-mail: 22838082@nwu.ac.za

\section{REFERENCES}

1. Abdel-Magid, M. F. (1979). Towards a better understanding of the role of measurement in Accounting. The Accounting Review, April: 346-357.

2. American Accounting Association. (1971), Report of the Committee on Foundations of Accounting Measurement. The Accounting Review, Supplement

3. American Institute of Certified Public Accountants. (1941), Committee on Terminology, Accounting Terminology Bulletin no 1, New York.

4. American Institute of Certified public Accountants, (1953), Committee on Terminology, Accounting Terminology Bulletin No. 1: Review and resume, New York: the institute.

5. Arthur Anderson \& Co. (1979), Cost of Government Regulation Study (New York: Business Roundtable)

6. Baiman, S. (1990), Agency Research in Managerial Accounting: A second Look. Accounting Organizations and Society, 15(4): 341-371.

7. Belkaoui, R. A. (1989), The Coming Crisis in Accounting, Quorum Books

8. Bierman, H., Jr. (1963), Measurement and Accounting, The Accounting Review, 38: 501-508

9. Boyce, B.R., Meadow, C.T., Kraft, D.H. (1994). Measurement In Information Science, Academic press limited.

10. Caws, P. (1959), Definition and Measurement in physics, in C. West Churchman and Philburn Ratoosh, eds. Measurement, Definitions, and theories, John Wiley \& Sons, Inc.

11. Chambers R.J, (1997), Wanted: Foundations of Accounting Measurement. Abacus, 34 (1): 36-47.

12. Churchman, C.W., and Ratoosh, P. (1959). Measurement, Empirical Meaningfulness and Three-Valued Logic, Wiley, New York

13. Decoene, S., Onghena, P. and Janssen, R. (1995). Representationalism under Attack. Journal of Mathematical Psychology, 39: 234-242.

14. Gilman, S. (1939), Accounting Concepts of Profit, Ronald Press

15. Goldberg, L. (2001), A journey into the accounting thought. Edited by: Leech, S.L Routledge, London

16. Gouws, D.G. and Van der Poll H.M. (2004), The integrity of information created through book entries. Meditari Accountancy research, 12 (1): 101-117.

17. Hornby. A.S. (2005), Oxford Advanced Learner's Dictionary of Current English, Oxford University Press, Oxford 
18. Ijiri, Y. (1967). The foundations of accounting measurement: a mathematical, economic and behavioural enquiry. Englewood Cliffs, NJ.Prentice -Hall

19. Ijiri, Y. (1975). Theory of Accounting Measurement, American Accounting Association

20. International Accounting Standards Board (IASB), 2009, International Financial Reporting Standards (IFRS) (2009): Including International Accounting Standards (IAS) and interpretations as at 1 January 2009.

21. Kirk, R.J. (2005). International Financial Reporting Standards In Depth, Volume 1: Theory and practice, CIMA Publishing, An Imprint of Elsevier, Linacre House, Jordan Hill, Oxford OX2 8DP, 30 Corporate Drive, Burlington, MA 01803.

22. Larson K., D. (1969), Implications of Measurement Theory on Accounting Concept Formulation, The Accounting Review, January: 38-47.

23. Littleton, A.C. (1953), Structure of Accounting Theory, American Accounting Association.

24. Luce, R. D., Krantz, D.H., Suppes, P. and Tversk, A. (1971), Foundations of Measurement, (Vol. 1) Additive and Polynomial representations, New York: Academic Press

25. Luce, R, D. and Narens, L. (1994), Fifteen Problems Concerning The Representational Theory of Measurement. Available, http://www.Imbs.uci.edu/personnel/Luce/1994/Luce\&Narens_Book\%20Chapter_1994.pdf, Accessed 2006/10/10.

26. Margenau, H. (1959), Philosophical Problems Concerning the meaning of Measurement in physics, in C. West Churchman and Philburn Ratoosh, eds. Measurement, Definition and theories, John Wiley \& Sons, Inc: $136-165$.

27. Mattessich R. (1964), Accounting and Analytical Methods, Homewood 3, Irwin

28. McLean, R. (2006), New Concepts in Measuring Value, in (Ed), Einstein in the Boardroom, John Wiley \& Sons, Inc.

29. Musvoto S.W. (2011) Implications Of The Crisis Of Objectivity In Accounting Measurement On The Development Of Finance Theory, International Business \& Economics Research Journal, Vol, 10(2) 2011

30. Musvoto S.W. \& Gouws D.G (2010) The concept of a scale in accounting measurement South African Journal of Economic and Management Sciences, Vol,13(4)2010

31. Narens, L. (2002). A meaningful justification for the representational Theory of Measurement, Journal of Mathematical Psychology, 46: 746-768.

32. Orbach, K.N. (1978). Accounting as a Mathematical Measurement Theoretic Discipline, Unpublished PhD Thesis, Texas A \& M University

33. Paton, W. A. and Littleton, A.C. (1940), An introduction to Corporate Accounting Standards, American Accounting Association

34. Ryan, B., Scapens, R.W., and Theobald, M. (2002), Research Method and Methodology in finance and Accounting, Second Edition, Mitcham, Surrey, International, Padstow, Cornwall.

35. Stamp E. (1981) Why can Accounting not become a Science like Physics? Abacus, June: 13-27.

36. Staubus, G. J. (2004), Two views of Accounting Measurement. Abacus, 40 (3): 265-279.

37. Sterling, R.R. (1979). Towards a science of Accounting, Accounting publications of Scholars book co.

38. Sterling, R. R. (1966), An Operational Analysis of Traditional Accounting, Abacus, December: 119-136

39. Sterling, R.R. (1968). The Going Concern: An Examination, The Accounting Review, July: 481-502.

40. Stevens, S.S. (1946). On the theory of scales of measurement, Science, 103: 667-680

41. Staubus, G. J. (1985). An induced Theory of Accounting Measurement, The Accounting Review, January, 60(1): 53-75.

42. Walker, R.G. and Jones, S. (2003), Measurement: A way forward, Abacus: 39 (3): 356-374.

43. Willet, R. J. (1987), An Axiomatic Theory of Accounting measurement, Accounting and Business Research: $155-171$.

44. Wolk, H.I., Tearney, M.G. and Dodd, J.L. (2001) Accounting Theory: A conceptual and Institutional Approach, South Western College Publishing. 
NOTES 